\title{
WILL ARABIC SURVIVE IN AUSTRALIA? PARTICIPATION AND CHALLENGES
}

\author{
Nadia Selim*
}

\begin{abstract}
Motivated by the need to preserve Arabic learning and teaching, this article acknowledges the importance of considering the various contexts in which Arabic is taught and learnt and its specific status therein. In this regard, the Australian context is underrepresented in the literature on Arabic language learning. This article will, therefore, shed some light on the specifics of the Australian context, in which Arabic is a language that struggles to attract sufficient numbers of learners in the senior years of school, thereby often calling into question the viability of university-level programs. With the viability of Arabic tertiary programs in Australia on the line, reversing such trends is a necessity. However, research on Arabic in the Australian context has been very limited. Therefore, this article will explore five language-specific issues that might underpin problematic participation in the learning of Arabic.
\end{abstract}

Keywords: Arabic, languages, participation, language policy, research.

\section{The Arabic Problem: Limited Participation}

The presence of Arabic in Australia can be traced back to the arrival of Muslim Makassar traders, who used Arabic for religious purposes. The Makassar traders built a relationship with the Australian Aboriginal community that has been described by Patrick Dodson as "the most successful encounter ever between any two cultures on this continent. Two cultures who met to trade and exchange commerce, two cultures that showed mutual respect and understanding of each others values, language, customs and laws." Evidence of the exchange abounds, with indications of Arabic having been present in Arnhem Land. ${ }^{2}$ This presence of Arabic as a language of religious practice continued with the subsequent arrival of a few Muslim Indian indentured labourers in the $1830 \mathrm{~s}^{3}$ and Afghan cameleers in the 1860s. ${ }^{4}$ These instances overlapped with the arrival of the Lebanese in the 1880 s, who expanded the scope of Arabic use. ${ }^{5}$

Today, Arabic remains a language of faith for 604,200 Australian Muslims, ${ }^{6}$ as well as a language of communication and culture for 321,728 Australian Arabs who use Arabic in their homes. ${ }^{7}$ In fact, Arabic is the third most widely spoken 
language in Australia. ${ }^{8}$ Additionally, since language is "central to diplomacy, managing Australia's national security and developing trade opportunities," Arabic is considered a means of "understanding the culture and faith of the Arabic speaking world" 10 and is seen as "more important for Australia than ever before." This extends the language's base of potential learners to the broader Australian population. However, in spite of this history and Arabic's communal as well as strategic value, participation is problematic at both the school and university levels.

Arabic was first reported in the Australian school system in 1975 "when it was taught to 306 pupils in two Catholic schools in New South Wales"12 (NSW). In 2001, the number of students participating in Arabic language study in the government sector stood at $8,614 .{ }^{13}$ In 2006, it was estimated that 25,449 students were studying Arabic in Australian primary and secondary schools, ${ }^{14}$ a drop from 31,844 in $2001 .{ }^{15}$ However, participation in Arabic learning has been "likened to a pyramid with many students being involved for short times when younger but gradually dropping out until only 8 per cent of Arabic speakers study Arabic in the final year of school." 16

Using data provided by the Research Unit for Multilingualism and CrossCultural Communication (RUMACCC), in 2009 Joseph Lo Bianco and Yvette Slaughter reported on the figures for participation across Australian schools for several languages in the year 2006. ${ }^{17}$ This data was presented on two separate pages of the publication and reflected some discrepancies, contributing to a need to present two totals. ${ }^{18}$ Nonetheless, when the year-by-year data was compiled (table 1) and presented graphically (figure 1), the outcomes supported statements made about the decline in Arabic language learning in later years of school.

\begin{tabular}{|c|c|}
\hline Grade & Enrolments \\
\hline Pre-Year 1 & 2,732 \\
\hline Year 1 & 2,743 \\
\hline Year 2 & 2,408 \\
\hline Year 3 & 2,572 \\
\hline Year 4 & 2,470 \\
\hline Year 5 & 2,396 \\
\hline Year 6 & 2,049 \\
\hline Year 7 & 1,332 \\
\hline Year 8 & 1,273 \\
\hline Year 9 & 886 \\
\hline Year 10 & 839 \\
\hline Year 11 & 480 \\
\hline Year 12 & 211 \\
\hline
\end{tabular}

Table 1: Compilation of Pre-Year 1 to Year 12 Arabic data from page 44 and page 50 of Lo Bianco and Slaughter 2009: Second Languages and Australian Schooling based on 2007 RUMACCC report 


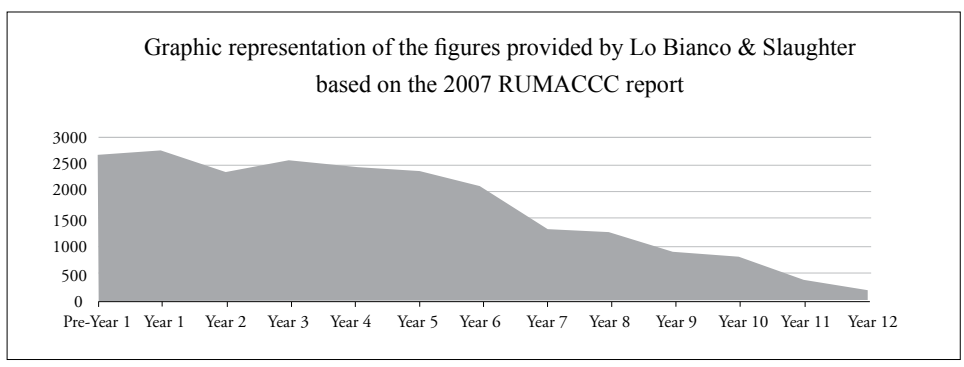

Figure 1: Representation of the enrolments in Arabic through school years

For a better idea of recent Year 12 Arabic participation figures, it is best to refer to data presented by the Australian Curriculum Assessment and Reporting Authority (ACARA). ACARA reports on various aspects of Australian education, including "the percentage of Year 12 enrolments in tertiary-recognised languages," 19 which is calculated "as a percentage of total enrolments in Year 12 languages other than English." ${ }^{20}$ The data presented here is available through the ACARA reporting portal. The total numbers and percentages of Year 12 students enrolled in languages are only available for the years 2010-2017. The figures have been compiled and averaged in table 2 .

\begin{tabular}{|c|c|c|}
\hline Year & $\begin{array}{c}\text { Y12 enrolments in } \\
\text { languages numbers }\end{array}$ & $\begin{array}{c}\text { Y12 enrolments in } \\
\text { languages percentages }\end{array}$ \\
\hline 2010 & 24,188 & 11.30 \\
\hline 2011 & 23,750 & 10.90 \\
\hline 2012 & 24,311 & 10.90 \\
\hline 2013 & 23,479 & 10.50 \\
\hline 2014 & 22,673 & 10.30 \\
\hline 2015 & 23,417 & 10.20 \\
\hline 2016 & 23,769 & 10.20 \\
\hline 2017 & 24,461 & 10.30 \\
\hline Average & $\mathbf{2 3 , 7 5 6}$ & $\mathbf{1 0 . 5 8}$ \\
\hline
\end{tabular}

Table 2: Compilation of total Year 12 enrolments in tertiary-recognised languages from 2010-2017

The percentages of enrolments from 2006-2017 per language are shown on the next page. These were extracted from a downloadable report ${ }^{21}$ and then averaged and displayed in descending order: 


\begin{tabular}{|l|c|c|c|c|c|c|c|c|c|c|c|c|c|}
\hline $\begin{array}{c}\text { Year / } \\
\text { Language }\end{array}$ & $\mathbf{2 0 0 6}$ & $\mathbf{2 0 0 7}$ & $\mathbf{2 0 0 8}$ & $\mathbf{2 0 0 9}$ & $\mathbf{2 0 1 0}$ & $\mathbf{2 0 1 1}$ & $\mathbf{2 0 1 2}$ & $\mathbf{2 0 1 3}$ & $\mathbf{2 0 1 4}$ & $\mathbf{2 0 1 5}$ & $\mathbf{2 0 1 6}$ & $\mathbf{2 0 1 7}$ & Average \\
\hline Chinese & 18.9 & 19.0 & 20.0 & 22.3 & 20.2 & 19.7 & 18.7 & 19.1 & 19.7 & 20.0 & 19.7 & 21.0 & $\mathbf{1 9 . 9}$ \\
\hline Japanese & 19.8 & 18.6 & 19.0 & 19.3 & 19.8 & 19.7 & 20.1 & 19.7 & 20.0 & 20.7 & 20.5 & 20.6 & $\mathbf{1 9 . 8}$ \\
\hline French & 18.2 & 18.7 & 19.0 & 18.5 & 19.6 & 20.1 & 21.1 & 20.9 & 20.6 & 20.1 & 19.9 & 18.5 & $\mathbf{1 9 . 6}$ \\
\hline Italian & 9.5 & 9.1 & 8.0 & 8.6 & 8.6 & 9.0 & 9.3 & 9.4 & 8.8 & 9.8 & 9.6 & 8.9 & $\mathbf{9 . 1}$ \\
\hline German & 9.1 & 9.4 & 9.0 & 7.7 & 7.8 & 7.6 & 7.7 & 7.5 & 7.8 & 7.2 & 7.4 & 7.1 & $\mathbf{7 . 9}$ \\
\hline Indonesian & 6.4 & 5.8 & 5.0 & 4.6 & 4.8 & 4.5 & 3.9 & 4.2 & 4.1 & 4.0 & 3.8 & 3.8 & $\mathbf{4 . 6}$ \\
\hline Spanish & 2.7 & 2.8 & 3.0 & 2.7 & 2.9 & 2.8 & 3.2 & 3.0 & 3.4 & 3.1 & 3.0 & 3.6 & $\mathbf{3 . 0}$ \\
\hline Vietnamese & 2.3 & 2.6 & 3.0 & 3.2 & 3.2 & 3.5 & 2.9 & 2.9 & 2.7 & 2.3 & 2.5 & 2.8 & $\mathbf{2 . 8}$ \\
\hline Greek & 1.8 & 2.5 & 2.0 & 2.1 & 2.2 & 2.0 & 2.1 & 2.2 & 2.4 & 2.3 & 2.2 & 2.2 & $\mathbf{2 . 2}$ \\
\hline Arabic & 2.0 & 1.9 & 2.0 & 1.7 & 1.7 & 1.9 & 1.7 & 1.7 & 1.8 & 1.7 & 2.0 & 2.2 & $\mathbf{1 . 9}$ \\
\hline Other & 9.3 & 9.6 & 10.0 & 9.2 & 9.2 & 9.2 & 9.2 & 9.5 & 8.8 & 8.9 & 9.5 & 9.3 & $\mathbf{9 . 3}$ \\
\hline ALL & 100 & 100 & 100 & 100 & 100 & 100 & 100 & 100 & 100 & 100 & 100 & 100 & $\mathbf{1 0 0}$ \\
\hline
\end{tabular}

Table 3: Percentage of Year 12 enrolments in tertiary-recognised languages, Australia, 2006-2017, provided by ACARA 2017 report

The data suggests that Year 12 enrolments in Arabic have averaged 1.9 per cent. over the stated period. This is comparatively low, especially when one notes that Arabic speakers constitute the third largest language community in Australia (after English and Mandarin/Chinese), ${ }^{22}$ that the Arabic language has religious appeal to Muslims, and the strategic value the language has to the broader Australian public. Naturally, the decline in participation results in low enrolment percentages in Year 12, which impacts university enrolments.

In 1946, Arabic was taught at an Australian university for the first time, at the University of Melbourne. ${ }^{23}$ Since then, Arabic has had an enduring but limited presence; Arabic was deemed a Moderately Taught Language (MTL) in 2006, ${ }^{24}$ which remained true in $2011,{ }^{25}$ with nothing to suggest this status has improved since. In fact, if anything, the support for Arabic in Australian universities seems to be waning. ${ }^{26}$ In the Australian context, MTLs have been defined as languages that are offered by less than 50 per cent and more than 10 per cent of Australian universities..$^{27}$ To put this in perspective, I note that there are 40 universities in Australia, ${ }^{28}$ which means that Arabic needs to be offered by more than four universities to maintain an MTL status. Fewer offerings would see it fall into the category of Less Commonly Taught Languages (LCTL). ${ }^{29}$

Data about university offerings through the years is fragmented. In 2006, Peter White and Richard Baldauf presented an aggregate of university offerings of Arabic between 1981 and $2005 .{ }^{30}$ In 2007, the Group of Eight leading universities $(\mathrm{GO} 8)^{31}$ addressed Arabic university offerings briefly, as did a report published by 
Anne McLaren in 2011..$^{32}$ In 2018, Jennifer Baldwin presented further information about offerings between 2011 and $2016 .{ }^{33}$ These figures have been collated in table 4 and show that, on average, Arabic has been offered by five universities for the past 35 years, thus barely making it into the category of MTLs.

\begin{tabular}{|l|l|l|}
\hline \multicolumn{1}{|c|}{ Researcher } & \multicolumn{1}{|c|}{ Year } & University offerings \\
\hline \multirow{3}{*}{$\begin{array}{l}\text { White \& Baldauf } \\
\text { (2006) }\end{array}$} & 1981 & 4 \\
\cline { 2 - 3 } & 1988 & 5 \\
\cline { 2 - 3 } & 1990 & 7 \\
\cline { 2 - 3 } & 1994 & 5 \\
\cline { 2 - 3 } & 1997 & 4 \\
\cline { 2 - 3 } & 2001 & 4 \\
\hline \multirow{5}{*}{$(2007)$} & 2002 & 5 \\
\hline & 2003 & 5 \\
\hline & 2004 & 5 \\
\hline GO8 & 2005 & 5 \\
\hline McLaren (2011) & 2009 & 5 \\
\hline Baldwin (2018) & 2011 & 5 \\
\cline { 2 - 3 } & 2014 & 7 \\
\cline { 2 - 3 } & 2016 & 4 \\
\hline \multirow{5}{*}{ Average } & 5 \\
\hline
\end{tabular}

Table 4: The number of universities offering Arabic between 1981 and 2016

It was recognised as early as 1991 that "student demand for Arabic is very weak, ${ }^{\prime 34}$ as none of the seven individual institutions offering Arabic in 1990 had exceeded 20 Equivalent Full-Time Student Units (EFTSU). ${ }^{35}$ In 1993, it was highlighted that it was necessary for Arabic programs to "at least be maintained at their present level, and if possible, expanded." ${ }^{" 36}$ However, years later in 2009 the combined total of university enrolments for Arabic at three universities (ANU, Melbourne and Sydney) stood at just 133 EFTSU, having risen from 55 EFTSU enrolments in 2001 in what constituted a 142 per cent increase at the time. ${ }^{37}$

Due to such low enrolments, Arabic's position at universities remains uncertain. ${ }^{38}$ For example, the University of South Australia attempted a collaborative partnership with Deakin University to teach Arabic and Italian between 2008 and 2011. ${ }^{39}$ However, enrolments were found to be extremely lopsided "with strong student numbers in Italian and smaller ones in Arabic," which ultimately "created a financial imbalance that challenged the collaboration's viability" and resulted in its abandonment at the end of 2011. ${ }^{40}$ Another example is that of the University of Western Sydney (UWS). In 2013, UWS decided to 
discontinue their Arabic program in spite of the fact that "a funding agreement between the Department of Education, Employment and Workplace Relations and the University of Western Sydney" specified "that Arabic was a Nationally Strategic Language and the University had to consult the Commonwealth government and obtain their approval before closing such a course." ${ }^{\prime 1}$ This was a truly curious decision for four reasons. Firstly, the university had an established program, first introduced in the $1980 \mathrm{~s} .{ }^{42}$ Secondly, the university was located in a region with one of Australia's biggest concentrations of Arabic speakers. ${ }^{43}$ Thirdly, the university had a partnership with the University of Melbourne and Griffith University in the National Centre for Excellence in Islamic Studies, which sought to serve the learning needs of the Muslim community ${ }^{44}$ in three Australian states. ${ }^{45}$ Fourthly, there are bigger numbers of teachers available to support Arabic programs in Sydney. Perhaps for these reasons, in the middle of 2014, it was reported that UWS was intending to reintroduce Arabic as their new vice-chancellor believed the earlier decision had been hasty. ${ }^{46}$

Only the future can tell whether Arabic programs will survive in Australia. However, it is now crucial to understand what may be deterring learners. It is important to note here that the concern is for Standard Arabic [or $\mathrm{fuS}-\mathrm{Ha}$ ], which is the literary variety of the language taught in schools and universities. Oral maintenance of Arabic dialects is said to be comparatively high in the Arab community ${ }^{47}$ It is also important to recognise that the Arabic problem is rooted within a broader concern for language participation in Australia, as languages are "fighting for their very survival," 48 with Year 12 student participation in languages averaging just 10.58 per cent between 2010 and 2017. Seeing that this is a broader problem, various explanations have been presented for poor participation in languages generally. For instance, it has recently been argued that the pressures of high school certification drive school students to make pragmatic decisions whereby they drop languages and focus on subjects that are more likely to benefit their high school examination outcomes ${ }^{49}$ It has also been suggested that perhaps a deep-seated "Anglo-fundamentalism" might be undermining the effectiveness of many language offerings. ${ }^{50}$

While the challenges facing all languages likewise apply to Arabic, I believe that there are also language-specific issues at play. This article will address five possible issues. Firstly, the negative impact stereotypical representations of Arabs and Muslims have on the participation of the broadest base of the Australian population, which is neither Arab nor Muslim. Secondly, the implications that the narrow definition of Arabic learners shaping learning in Australia has had for curriculum design. Thirdly, the reputation Arabic has earned for being notoriously difficult. Fourthly, the challenge diglossia presents for Arab learners in Australia, as well as for all non-Arab learners. Finally, the lack of research that has led to a 
poor understanding of non-Arab learners and their learning needs. I recognise that these issues overlap with each other and with other issues affecting participation in languages; however, I introduce them separately to draw attention to them as areas in need of research.

\section{Stereotypes of Arabs and Muslims deter non-Arab, non-Muslim Australians}

Although Arabic has had an enduring presence in Australia and is considered one of the languages of wider teaching, ${ }^{51}$ it has been suggested that negative stereotypes deter non-Arab Australians from learning it. In 1993, it was stated that "Arabic has a poor image in the non-Arabic background population. Our impression is that mainstream attitudes to Arabs are negative stereotypes, and that these flow on to the Arabic language." ${ }^{52}$ While this statement does not identify who exactly is susceptible to these stereotypes or provide empirical evidence to support their impact, there is sometimes wisdom in anecdote. More importantly, this statement was made in the published outcomes of the largest research study on Arabic learning in Australia, thus awarding it some credibility. Therefore, reflection on the history of the Arab community is necessary in order to reveal some of the stereotypical images that may be deterring non-Arab, non-Muslim Australians (or the broad base of the population) from the learning of Arabic.

The first Arab migrants to Australia were mostly Lebanese. Initially, they were categorised as $\operatorname{Asian}^{53}$ because Lebanon was a Syrian province under Ottoman rule. ${ }^{54}$ They were also called Syrians, Ottomans and Assyrians "when people misheard the term 'a Syrian'. This continued until around the 1930s to 1950s when they came to be referred to as Lebanese with the development of an independent Lebanon." ${ }^{55}$ Like other Asians and non-Europeans, the Lebanese suffered from the "discriminatory practices of Colonial legislation and practices under the federal White Australia Policy." ${ }^{56}$ However, because they looked "physically similar to Europeans, were overwhelmingly Christian, and tended to come with wives and families, many in the wider community considered them to be a special case, and legislative provisions, especially the 1920s Nationality Act, were relaxed to accommodate them." ${ }^{57}$

Arabs continued to arrive in waves that often corresponded to periods of upheaval in the Middle East. "Between 1947 and 1975 there were significant migrations from Lebanon and Egypt, due largely to the political situation in Egypt and Lebanon and the Arab-Israeli War of 1967 and Australia's push for immigrants. Following the outbreak of the civil war in Lebanon in 1975 there was a large influx of mainly Muslim immigrants and the Lebanese-born population doubled in 2 years. ${ }^{58}$ In 2008 it was noted that the resultant population was 
varied in its religious affiliations, "with over 50 per cent belonging to Christian denominations and 40 per cent to Muslim groups." ${ }^{\text {" }}$ Most of the community was "affiliated to one of the Maronite, Melkite or Orthodox churches or to Sunni or Shi'a mosques." ${ }^{\circ 0}$ Today, the Lebanese still represent the largest community of Arabic speakers, followed by Egyptians and Iraqis. ${ }^{61}$

There are examples of successful integration, with various Arab-Australians penetrating political, media and intellectual circles. However, these are mostly overshadowed by the sentiment that the "adaptation path has not been easy for the Lebanese immigrants and their Australian-born children." ${ }^{2}$ The population is relatively young ("69 per cent are under 35 ") ${ }^{63}$ but only "19 per cent of the population has a formal qualification. Employment levels are low, with only 40 per cent of the community between 15 and 65 in the workforce and family incomes are also correspondingly low." ${ }^{4}$ The educational success of the community, "and school retention rates are lower for Arabic-speaking youth than the average in New South Wales." ${ }^{65}$ Additionally, some Lebanese youth were implicated in criminal gangs and wound up in remand centres.

In public discourse, the news media often blurs the lines between the terms Arab, Lebanese, Middle Eastern and Muslim. ${ }^{66}$ "Nightly news bulletins are often filled with stories of crime, war, injustice and political turmoil across the Arab world, with many of these portraying Australian Arabs or Muslims in negative ways - for example, as criminals or terrorists." ${ }^{67}$ Although fictional portrayals are rare, often the Arab-Australian "is still 'othered', usually through the problematisation of their ethnic or religious background." ${ }^{68}$ Like members of other immigrant communities in the past, many Lebanese men are depicted as "dole bludgers." ${ }^{\circ 9}$ Most damaging and prevalent of all, however, are the depictions of the "thug" or "terrorist."

Tensions around the presence of Arabs and Muslims were heightened by the events of 9/11 and the subsequent War on Terror. The invasions of Iraq and Afghanistan also contributed to the "reemergence of fear toward the Muslim/ Arab Other." ${ }^{\text {71 }}$ Combined with vilification by the media 'shock jocks,' this situation culminated in 2005, with the unfortunate events that took place in the Sydney suburb of Cronulla. There a series of race riots and mob violence broke out. Today, dog-whistle politics still perpetuates divisive narratives and heightens tensions around the presence of Arabs and Muslims in Australia.

It is saddening that a language with such history, heritage and value as Arabic needs a public relations campaign. Arabic is "logical, sophisticated and demands a disciplined mind. The study of Arabic itself immediately defies and dispels the stereotypical image of simple barbaric tribes and backward terrorists." 72 It was also noted that the wider Australian community would benefit from learning Arabic because this would assist in "the correction of myths and stereotypes about 
the Arab World." ${ }^{73}$ However, as there "is no high profile organisation such as the Goethe Institute, Alliance Francaise or Japan Foundation to correct the image, and little prospect of one emerging in the near future, ${ }^{, 74}$ we are in a catch-22 situation. Although Australians need to learn Arabic to correct their views of Arabic, Arabs, Muslims and Islamic civilisational history, the stereotypes stop them from coming to learn.

\section{Arabic Learners are Defined Narrowly}

Despite the various challenges experienced by the Arab-Australian community, a highlight of the Australian context is its multi-cultural policy, which provides generously for the learning and teaching of Arabic. These provisions emanate from Australia's broader National Policy on Languages (NPL). Australia was the "first English-speaking country to formulate an explicit language policy, and the first in the world to have a multilingual policy." 75 The policy articulated four main guiding principles: the acquisition of English competence for all Australians, maintenance and development of Languages Other Than English (LOTE), provision of services in LOTE, and the provision of opportunities to learn second languages. ${ }^{76}$

It might be from here that the narrative of "language maintenance" emanated. This narrative is principled in its origins and born out of a deep respect for the rights of communities to maintain their languages in an inclusive multi-cultural society. However, it may also be why bilingualism remains largely "confined to Aborigines and migrants who have added English to their first language." ${ }^{.77}$ Thus, in the case of Arabic, the language maintenance narrative led to Arabic learners being viewed through a narrow lens of ethnic affiliation, which has undermined opportunities for Arabic learning among both the non-Arab Australian Muslim population (i.e. whose affiliation is primarily religious) and the wider Australian community.

As a result, in 1994 it was ascertained that "Arabic is currently being taught at primary school level in a largely language maintenance framework, mainly in New South Wales and Victoria where it has its broad base. ${ }^{178}$ In the tertiary sector, it was noted that, although Arabic was a language of international significance, it seemed to suffer from the "same self-limiting perception that characterises it in schools: that it is a 'community language' of interest only to Australians of Arabic background." 79

The prevalent assumption that learners of Arabic are Arabs means that programs are designed for them, which has inadvertently led to all other learners grappling with content that is inherently inappropriate for them. This was recognised in 1993, prompting a team of researchers to ask if serious attempts 
could be made to consider non-Arabic background learners of the language by "designing comprehensive courses that take into account the special problems of learning Arabic as a genuine second language" $" 80$ Unfortunately, a restrictive definition of learners still shapes Arabic learning in the Australian schooling sector. ACARA thankfully oversaw the development of a national curriculum for Arabic between the years 2011 and 2016, when it was finally released. ${ }^{81}$ However, the curriculum context statement explicates that it was designed with Arab background learners in mind ${ }^{82}$ These learners were defined as:

students who have exposure to Arabic language and culture, and who may engage in active but predominantly receptive use of Arabic at home. The range of learners within the Arabic background language learner pathway is diverse, defined for the most part by different waves of migration, and their use of Arabic may extend beyond the home to everyday interactions with Arabic-speaking friends and involvement in community organisations and events. Other learners may have been born in an Arabic-speaking country, where they may have completed some education. ${ }^{83}$

The justification for this decision was that Arabs constituted the "dominant cohort of learners in the Australian context." ${ }^{14}$ In being pragmatic, however, ACARA inadvertently contributed to the perpetuation of a narrow definition of Arabic learners bound by ethnic affiliations. Therefore, though Australia has taken strides towards building a curriculum, it has built one that has not taken non-Arab Muslims or the broader base of Australian learners into account. This will invariably lead to scenarios in which the curriculum is difficult, irrelevant or problematic in its enactment, contributing to lower participation among nonArab students.

\section{Arabic's Reputation for being Notoriously Difficult}

Arabic has a reputation for being notoriously difficult to learn. Paul Stevens highlights that "popular wisdom in the United States often holds Spanish to be easier for English speakers to learn than many other languages, including French or German. Even more than German, languages such as Chinese or Arabic are reputed to be particularly difficult." ${ }^{85}$ In the case of Arabic, this seems to be true of the Australian context as well. For instance, in the Campbell report, which argued for the need to promote the study of Arabic among non-Arab learners, the authors say, in rather condemnatory fashion, that Arabic's "(deserved) reputation as being difficult is another deterrent." ${ }^{" 66}$ Stevens explains that "there is a greater- 
than-ever emphasis on the need for learning Arabic, both Standard and Colloquial. In spite of this, some prospective students may shy away from studying Arabic because of this language's reputation for being among the hardest to learn." ${ }^{87}$ It is, therefore, important to reflect on the perceived difficulty of Arabic.

From the point of view of an English speaker, learning Arabic requires accomplishing some challenging achievements. These include learning a different writing system; conforming to a different grammar structure that includes attached pronouns, inflected nouns, and conjugated verbs; and learning a system of derivational morphology. In the USA, the "Foreign Service Institute (FSI) categorised languages according to their difficulty from the perspective of the native speaker of English and based their classifications on the number of hours needed to attain proficiency in the target language (TL). The fourth category, which includes Arabic, Japanese, Chinese and Korean, is the hardest. For this category, some estimates indicate that at least sixty-eight weeks of fulltime instruction are needed to attain fluency, while others suggest the figure is closer to eighty-eight weeks." ${ }^{88}$ It is also noted that, for category four, the number of instructional hours may fall between 2,400-2,760 hours. ${ }^{89}$ In many ways, these figures are relevant to all non-Arab English-speaking learners of Arabic in Australia and call into question the two-hours per week provision made for Arabic in some schools. ${ }^{90}$

While it is undeniable that Arabic has its complexities, it is important to note that so do all languages. In fact, the FSI classification was challenged in an academic study of various languages, completed by Paul Stevens in 2006. ${ }^{11}$ After much analysis, Stevens concluded that:

Surprisingly, even a language such as Spanish, reputed to be particularly simple, is in at least some respects linguistically more complex than Arabic. Spanish, as well as other languages, is more complicated than Arabic in its verb tenses; French is more complicated in its phonemeto-grapheme correspondence; German, Polish, and Greek, in their complex case inflections; Japanese in its complicated writing system. Even Standard Arabic is "easier" than some other languages in having a very regular verb conjugation, only two genders, only three cases, and a very regular writing system. Colloquial Arabic is even "easier" than Standard.

Although no one should claim that Arabic is an "easy" language, as far as linguistic structural factors are concerned, Arabic does not deserve to be placed in the most difficult category. When seen in the context of other languages, it is not as difficult, relatively speaking, as is commonly believed. This is not to ignore the difficult aspects of Arabic 
or to pretend they do not exist. They do exist. But their overall effect on the learnability of Arabic is, in my judgment, exaggerated. ${ }^{92}$

This conclusion, coupled with reflection on the 2017 Year 12 language enrolments in Australia, raises questions. For instance, why did 20.6 per cent of Australia's Year 12 language enrolments go to Japanese in 2017 when it has a much more complicated writing system than Arabic? Or, why have Japanese enrolments been almost consistently 10 times greater than Arabic enrolments? Is the encouragement of business with Asia contributing to this? If so, why is Arabic not as appealing when it is classified as Asian and when the Arabicspeaking world is home to four of the top ten sovereign wealth funds (United Arab Emirates, Kuwait, Saudi Arabia, and Qatar)? Why did French, with its more complex phoneme-to-grapheme correspondence, attract 18.5 per cent of enrolments when Arabic attracted only 2.2 per cent? What drives the constantly higher French enrolments? Why are Spanish and Vietnamese enrolments increasing when Arabic is not? Why is declining Indonesian still doing much better than Arabic? It is likely that Arabic's reputation as a difficult language to learn affects enrolments.

So, why has Arabic earned this reputation? It is possible that the prevalence of poor pedagogical approaches contributes to this. While Arabic is not as difficult as it is made out to be, the way it is taught might perpetuate a reputation for being difficult. In this context, attention has been drawn to the grammar-intensive approaches that prime translation and memorisation at the expense of other language skills. ${ }^{93}$ Another possible explanation may relate to known concerns about curriculum, texts, and resources. ${ }^{94}$ In Australia, for example, there is the persistent absence of a curriculum designed for non-Arab learners. In any case, much work needs to be done to remediate the negative perceptions of the Arabic language and its learnability.

\section{Diglossia and Diversity Challenge Arab-Australians as well as other Learners}

Diglossia is well recognised in the broader literature on Arabic. ${ }^{95}$ In fact, "Arabic is held up as one of the classic examples of diglossia" ${ }^{96}$ because of the co-existence of dialects ('aam-iy-yah) and Standard Arabic $(f u S-H a)$. Arabs tend to converse in a dialect, which is perceived as the lower variety of the language, but read and write in Standard Arabic, which is perceived as the higher variety. ${ }^{97}$ Arabs typically esteem the standard variety and view vernaculars as slang or improper. The standard variety serves as a language of unity for non-Muslim Arabs and Arab Muslims. Standard Arabic is also the language of Islamic scripture and 
is therefore of interest to both Arab Muslims and non-Arab Muslims alike as the traditional lingua franca of Islam. Standard Arabic is also important for all learners who wish to access Arabic news media, literary content, or understand the language as used in formal contexts. While diglossia is the norm that binds Arabs in the Arabic-speaking world, ${ }^{98}$ it is known to trouble non-Arab learners because the Arabic learned in a classroom context may not correlate with various spoken varieties encountered outside the classroom. However, it seems that for Arabs living in diaspora communities, diglossia also proves challenging.

Given that Arabic learning provisions have generally been designed for Arab Australians, the latter should cruise through their Arabic learning journey. However, the declining numbers in senior schooling years suggests that Arab-Australian learners are challenged by diglossia as well. One study from over 25 years ago provided some insight. Included in the Campbell report published in 1993, this study investigated Year 11 students and provided some insight into their attitudes, motivations and profiles. ${ }^{99}$ In total, 67 students replied to the researcher's questionnaire, 95.6 per cent of whom were Lebanese and the remaining 4.4 per cent Egyptian. ${ }^{100}$ They all spoke Arabic at home with parents, relatives and family friends. ${ }^{101}$ "The students came from seven NSW and one Victorian High School, with the bulk (79.1 per cent) from two Sydney government schools." 102 The study revealed that, although they had all taken Arabic in Year 10, "nearly half (47.8 per cent) had discontinued in Year 11." ${ }^{103}$ The report then detailed the reasons for discontinuation, which included the difficulty of the subject, dislike for the teacher, and too many native speakers in the class. ${ }^{104}$ These three reasons demand deliberation.

The fact that the students cited subject difficulty as the first problem suggests Arab-Australians could be struggling with diglossia, which may be turning them away from Arabic language learning. Some insight can be gained from an autobiographical account of Arabic learning published in 2012, in which Cruickshank notes that in a tertiary Arabic program the "pronunciation of Arabic background speakers was always corrected. During class sessions when students were called up to write on the board, points were made about the problems of Arabic background speakers with letters/sounds such as tha, jim, dhal and ghayn. I noted that after the third lesson the Arabic background speakers tended to sit together and leave classes early." 105 Similarly, in a college program, Cruickshank notes that the teacher explained to a student who stated she just wanted to learn Lebanese Arabic that "Lebanese was not proper Arabic and that students had to learn the 'proper language' before they could speak it." 106 While these two cases suggest that there are pedagogical questions to be asked, they also show the clash between the two types of Arabic within the learning context.

In the Australian context, it has been suggested that within immigrant Arab communities it is likely for diglossia to come "under strain especially for the 
emerging second generation as three codes - colloquial Arabic, Standard Arabic and English - vie for their share of the communicative load." 107 Since no classroom can recreate the sociolinguistic factors that give rise to the development of an ability to move fluidly between two forms of Arabic, ${ }^{108}$ the complaint "but that is not how we say it" will undoubtedly emerge as learners attempt to acquire new pronunciation, unfamiliar words and strange word order. It has been hypothesised that this struggle may lead Arab students to view Standard Arabic "as a remote code whose usefulness and cultural significance is in question. At the same time, the negative attitude of Arabs to their colloquials could eventually be the only attitude that young Arabic speakers have towards Arabic as a whole." 109

In addition to the differences between spoken varieties and Standard Arabic, Arab-Australian learners also have to grapple with the fact that there may be numerous spoken varieties of Arabic in the classroom. This reality is further complicated by the recognised diversity of Arab learners' linguistic abilities in diasporic contexts. For instance, an Arab student may have two Arabic-speaking parents and have used or heard one of the Arabic dialects at home, or they may have one Arab parent and have not used or heard any Arabic at home, ${ }^{110}$ or they may have just migrated from the Arab world. Such complexities might explain why Arab students complain about the presence of too many native speakers in the classroom.

Although diglossia has and will continue to challenge all non-Arab learners, it seems to present problems for Arab-Australian learners too. It is hard to ascertain how these complexities play out in different schools or how educators manage them because research on Arabic language acquisition in Australia is limited.

\section{We do not Understand the Outlooks of non-Arab Learners}

The paucity of research on Arabic learning in the Australian context is problematic. Campbell et al. (1993) have stated that post-graduate research on "Arabic language and linguistics should be encouraged so that a sound academic base is developed in Australia." 111 The 1991 Leal report recommended that an advisory council on Arabic and Middle Eastern Studies be established in order to strengthen Arabic Studies. This council was expected to provide proposals for the development of these subjects, particularly in relation to making them attractive to non-Arabic speaking students. ${ }^{112}$ In 1993, Campbell and his team wondered how Arabic learning could be made "as desirable and as attractive as, say, the study of Japanese or even French." 113 However, since the 1990s, very little Australian research has been done to address the needs of non-Arab learners, their perspectives, identities, or even the very basics of their experiences of language learning. 
This problem is acute in terms of young non-Arab learners. In fact, in the Australian context, the voices and perspectives of those learners seems to be absent. However, in a PhD thesis completed in 2013, Peter Jones investigated whether Islamic schools inculcated values that were compatible with those of Australia. ${ }^{114}$ In that thesis, Arabic was considered a faith topic and the views of former students were solicited about their memories of learning it. The most important conclusion drawn from the sections dedicated to Arabic was that former 'students' opinions of Arabic were influenced by their existing language proficiency, with the more favourable views being held by students who were of Arabic speaking backgrounds and the less favourable views being held by students of non-Arabic speaking backgrounds." ${ }^{115}$ The study suggests some students complained bitterly about Arabic learning. ${ }^{116}$ However, the research was not focused on Arabic and much work still needs to be done.

In fact, many questions about the learning of Arabic by non-Arabs in Australia remain unanswered. For instance, are non-Arab learners a monolith? Are all non-Arabs turned away by negative stereotypes, whether they are IndigenousAustralians, Anglo-Australians, European-Australians or Asian-Australians? Do non-Arab Muslim learners studying at Islamic schools want the same things as Anglo-Australians and non-Arab Muslim-Australians studying Arabic at public schools? Do Indigenous-Australians who have a historical Islamic connection seek Arabic learning? How many Anglo-Australian students study Arabic? Do non-Arab Muslim-Australians want the same things out of their Arabic learning experience as their Arab Muslim counterparts? Are there shared themes in the various contexts of Arabic learning? We simply do not know, and this begs the question: how can we make learning more appealing to students whom we do not really know or understand?

Until we make serious efforts to understand non-Arab learners in the Australian context, we will invariably fail to promote the learning of Arabic among them. In this regard, non-Arab Muslim learners of Arabic should be given priority for three reasons. Firstly, we need to extend the findings of Peter Jones. Secondly, the religious affiliation of these individuals make them more inclined to learn Arabic in order to complete daily religious practices and enhance their religious knowledge. Thirdly, it has been argued that non-Arab Muslim learners are not affected by the negative Arab stereotypes that might influence participation in the wider Australian community. ${ }^{117}$ 


\section{Conclusion}

Arabic learning is important not only for Arab Australians and non-Arab Muslim Australians, but for the whole of Australia itself. However, attrition during school years and the very low enrolments seen at universities continue to threaten the survival of Arabic learning in the Australian context, especially if genuine attempts are not made to understand the reasons underpinning student disinterest. This paper has sought to present some possible language-specific explanations for this phenomenon. It is hoped that, by shedding light on these issues, further research will be undertaken. It is crucial that:

- Explorations are undertaken of various learning contexts, cohorts of learners, and school-aged students who choose not to learn Arabic.

- Researchers and practitioners try to gain insight into the impact stereotypes have on the broader base of Australian learners.

- Researchers investigate the impact of narrow conceptions of learners on curricular design, pedagogical equity and inclusion.

- Attention is awarded to the complications of diglossia.

- Research is undertaken to gain a better understanding of the pedagogical approaches and resources used to teach Arabic, and whether they underscore the reputed difficulty of Arabic.

- Researchers solicit the perspectives and voices of non-Arab learners of Arabic on Arabic learning in Australian schools, for which it may be prudent to prioritise Muslim non-Arab learners.

\section{Notes}

* Nadia Selim is an Arabic teacher. Nadia holds a Master's degree in Applied Linguistics (University of Queensland). Nadia taught at the Institute of Modern Languages (University of Queensland) and is a $\mathrm{PhD}$ candidate and researcher at the Centre for Islamic Thought and Education at the University of South Australia.Email: nadia.selim@unisa.edu.au.

1. Patrick Dodson, 'Key Note Address - the First Encounter by Muslim People and the Aboriginal Australians,' Muslim Students at Australian Universities - Access, Inclusion and Success Conference (Crowne Plaza Hotel Parramatta: University of Western Sydney, 2007). Senator Patrick Dodson is a Yawuru man from Broome and former Chairman of the Council for Aboriginal Reconciliation.

2. Regina Ganter, 'Remembering Muslim Histories of Australia,' La Trobe Journal 89 (2012): 57. 
3. Heather Foster, 'The First Indians: The Bruce and Gleeson Indentured Labourers in Nineteenth Century South Australia,' Journal of the Historical Society of South Australia 39 (2011): 22.

4. Regina Ganter, 'Muslim Australians: The Deep Histories of Contact,' Journal of Australian Studies 32, no. 4 (2008): 487.

5. Ken Cruickshank, 'Arabic-English Bilingualism in Australia,' in Encyclopedia of Language and Education, ed. Jim Cummins and Nancy H. Hornberger (New York: Springer, 2008), 282.

6. Australian Bureau of Statistics, 'Religion in Australia: 2016 Census Data Summary'.

7. Australian Bureau of Statistics, 'Census Reveals a Fast Changing, Culturally Diverse Nation.'

8. Ibid.

9. Group of Eight, 'Languages in Crisis: A Rescue Plan for Australia' (2007), 6. Available at: https://www.aftv.vic.edu.au/resources/whylearnfrench/ Languages_in_crisis.pdf

10. Ibid.

11. Ibid.

12. Paulin G. Djite, From Language Policy to Language Planning: An Overview of Languages Other Than English in Australian Education, ed. Languages Literacy Inst Australian National, Deakin (Deakin: National Languages and Literacy Institute of Australia, Ltd, 1994), 110.

13. Timothy J. Curnow, 'Participation in Languages Education in Australian Schools : What Do We Know, and What Does It Mean Anyway?' in Languages in Australian Education: Problems, Prospects and Future Directions, ed. Anthony J. Liddicoat and Angela Scarino (Newcastle upon Tyne: Cambridge Scholars, 2010), 28.

14. Joseph Lo Bianco and Renata Aliani, Language Planning and Student Experiences: Intention, Rhetoric and Implementation, ed. Nancy H. Hornberger and Colin Baker, vol. 93: Bilingual Education \& Bilingualism (Bristol: Multilingual Matters, 2013), 42. This is the most recent participation figure found.

15. Michael Clyne, Australia's Language Potential (Sydney: University of New South Wales Press, 2005), 113.

16. Cruickshank, 'Arabic-English Bilingualism in Australia,' 287.

17. Joseph Lo Bianco and Yvette Slaughter, 'Second Languages and Australian Schooling,' Australian Education Review 54 (2009): 44 and 50.

18. Ibid. On page 44, it is stated that: "Data drawn from 22 of 24 education jurisdictions (excluding NSW Catholic schools and Tasmanian independent schools) shows the range of primary languages. Some student data were not available by year level but as grouped information (e.g. as a total for each language at the primary level rather than by year level). This data has been included in the Total II column." On page 50, it is stated that; "Some data supplied by jurisdictions was according to non-year groupings and appears discretely, in the Total II column."

19. Assessment and Reporting Authority (ACARA) Australian Curriculum, Number and Percentage of Year 12 Students Enrolled in Tertiary-Recognised Subjects, 
by Learning Area and Sex, Australia 2017. Available at: http://www.acara.edu. au/reporting/national-report-on-schooling-in-australia-data-portal/year-12subject-enrolments\#view2 (Accessed on: 6 March 2019).

20. Ibid.

21. Ibid.

22. ABS, 'Census Reveals a Fast Changing, Culturally Diverse Nation.'

23. Jennifer Baldwin, 'The Place of Arabic Language Teaching in Australian Universities,' History of Education Review 47, no. 1 (2018): 77-8.

24. Peter White and Richard B Baldauf Jr, Re-Examining Australia's Tertiary Language Programs: A Five Year Retrospective on Teaching and Collaboration (Brisbane: University of Queensland, 2006), 8.

25. Kerry Dunne and Marko Palvyshyn, 'Endangered Species? Less Commonly Taught Languages in the Linguistic Ecology of Australian Higher Education,' Babel 47, no. 3 (2013), 7.

26. Baldwin, 'The Place of Arabic Language Teaching in Australian Universities,' 82.

27. Dunne and Palvyshyn, 'Endangered Species?' 6.

28. There are a total of 43 universities in Australia, 40 of which are Australian as per Future Unlimited, 'Universities and Higher Education.' Available at: https:// www.studyinaustralia.gov.au/english/australian-education/universities-andhigher-education (Accessed on: 18 January 2019).

29. Dunne and Palvyshyn, 'Endangered Species?' 6.

30. White and Baldauf Jr, Re-Examining Australia's Tertiary Language Programs, 8.

31. Group of Eight, Languages in Crisis, 6.

32. Anne McLaren, Asian Languages Enrolments in Australian Higher Education 2008-2009 (n.p: Asian Studies Association of Australia, 2011), 8.

33. Baldwin, 'The Place of Arabic Language Teaching in Australian Universities,' $82-3$.

34. Robert B. Leal, Widening Our Horizons: Report of the Review of the Teaching of Modern Languages in Higher Education, vol. 1 (Canberra: Australian Government Publishing Service 1991), 169.

35. Ibid.

36. Stuart Campbell et al., Unlocking Australia's Language Potential: Profiles of 9 Key Languages in Australia, vol. 1 (Canberra: National Languages and Literacy Institute of Australia, 1993), iv.

37. McLaren, Asian Languages Enrolments in Australian Higher Education 20082009, 8.

38. Baldwin, 'The Place of Arabic Language Teaching in Australian Universities,' 82.

39. Dunne and Palvyshyn, 'Endangered Species?' 14.

40. Ibid.

41. Baldwin, 'The Place of Arabic Language Teaching in Australian Universities,' 82.

42. Ibid.

43. Ibid.

44. Ibid.

45. Ibid. 
46. Ibid.

47. Cruickshank, 'Arabic-English Bilingualism in Australia,' 282.

48. Neil Langdon Murray, 'Discussion: Languages Education in Australia: Shaky Data, Disjointed Policy, and a Chicken and Egg Problem,' in Languages in Australian Education: Problems, Prospects and Future Directions, ed. Anthony J. Liddicoat and Angela Scarino (Newcastle upon Tyne: Cambridge Scholars Publishing, 2010), 87.

49. Sally Sitou, 'Atars to Blame for Fall in Language Study,' (news release, 23 April 2018). Available at: https://sydney.edu.au/news-opinion/news/2018/04/23/ atars-to-blame-for-fall-in-language-study.html (Accessed on: 28 December 2018).

50. Mario Daniel Martin, 'Permanent Crisis,Tenuous Persistence: Foreign Languages in Australian Universities,' Arts and Humanities in Higher Education 4, no. 1 (2005): 53-75.

51. Djite, From Language Policy to Language Planning, 19.

52. Campbell et al., Unlocking Australia's Language Potential, 68.

53. Paul Convy and Anne Monsour, Lebanese Settlement in New South Wales: A Thematic History (Ultimo: Migration Heritage Centre, 2008), 1.

54. Ibid., 2.

55. Ibid.

56. Ibid., 1.

57. Ibid.

58. Cruickshank, 'Arabic-English Bilingualism in Australia,' 282.

59. Ibid.

60. Ibid., 284-5.

61. Mostefa Abdelhadi, 'Arabic Language Maintenance among the Arabic-Speaking Community in the Regional Queensland City of Toowoomba, Australia,' Unpublished PhD Thesis, University of Southern Queensland (2016), 8.

62. Ronald Taft and Desmond Cahill, 'Mother Tongue Maintenance in Lebanese Immigrant Families in Australia,'Journal of Multilingual and Multicultural Development 10, no. 2 (1989): 131.

63. Cruickshank, 'Arabic-English Bilingualism in Australia,' 282.

64. Ibid.

65. Ibid.

66. Mehal Krayem, Heroes, 'Villains and More Villains: Representations of Arab Men on Australian Screens,' Unpublished PhD Thesis, University of Technology, Sydney (2014), 61.

67. Ibid., 78.

68. Ibid., 79.

69. Ibid., 80 .

70. Ibid., 79.

71. Ibid., 95.

72. Victorian Arabic-Speaking Community Workers Network, quoted in Campbell et al., Unlocking Australia's Language Potential, 63.

73. Ibid.

74. Ibid., 68.

75. Martin, 'Permanent Crisis, Tenuous Persistence,' 53. 
76. Joseph Lo Bianco, 'Making Language Policy: Australia's Experience,' in Language Planning and Education in Australasia and the South Pacific, ed. Richard B. Baldauf and Allan Luke (Philadelphia: Multilingual Matters Ltd., 1990), 59.

77. Martin, 'Permanent Crisis, Tenuous Persistence', 54.

78. Djite, From Language Policy to Language Planning, 110.

79. Leal, Widening Our Horizons, 61.

80. Campbell et al., Unlocking Australia's Language Potential, 47.

81. Assessment and Reporting Authority (ACARA) Australian Curriculum, 'Languages.' Available at: http://www.acara.edu.au/curriculum/learning-areassubjects/languages-main (Accessed on: 19 January 2019)

82. Australian Curriculum, Assessment and Reporting Authority (ACARA), 'Arabic: Context Statement.' Available at: https://www.australiancurriculum. edu.au/languages/arabic/context-statement (Accessed on: 24 April 2017). Assessment and Reporting Authority (ACARA) Australian Curriculum, 'Arabic: Context Statement.' Available at: https://www.australiancurriculum. edu.au/f-10-curriculum/languages/arabic/context-statement/ (Accessed on: 14 January 2019). The 2019 link now supersedes the 2017 link.

83. 'Arabic: Context Statement.'

84. Ibid.

85. Paul B. Stevens, 'Is Spanish Really So Easy? Is Arabic Really So Hard?: Perceived Difficulty in Learning Arabic as a Second Language,' in Handbook for Arabic Language Teaching Professionals in the $21^{\text {st }}$ Century, ed. Kassem M. Wahba, Zeinab A. Taha, and Liz England (New York: Routledge, 2006), 35.

86. Campbell et al., Unlocking Australia's Language Potential, 68.

87. Stevens, 'Is Spanish Really So Easy?' 61.

88. Nadia Selim, 'Arabic Teaching at Australian Islamic Schools: A Call Framework,' in Islamic Schooling in the West: Pathways to Renewal, ed. Mohamad Abdalla, Dylan Chown, and Muhammad Abdullah (Melbourne: Palgrave Macmillan, 2018), 286.

89. Stevens, 'Is Spanish Really So Easy?' 37.

90. Selim, 'Arabic Teaching at Australian Islamic Schools' 286.

91. Stevens, 'Is Spanish Really So Easy?' 35.

92. Ibid., 62.

93. Selim, 'Arabic Teaching at Australian Islamic Schools', 287-90; Nadia Selim, 'Arabic, Grammar, and Teaching: An Islamic Historical Perspective,' International Journal of Islamic Thought 13 (2018):80-1; Nadia Selim, 'Muslim Societies' Ambivalence to Arabic: Reasons, Manifestations and Consequences,' International Journal of Islamic Thought 11 (2017): 36-8.

94. Selim, 'Muslim Societies'Ambivalence to Arabic:', 36-9.

95. Mahmoud Al-Batal, 'Diglossia Proficiency: The Need for an Alternative Approach to Teaching,' in The Arabic Language in America, ed. Aleya Rouchdy (Detroit: Wayne State University Press, 1992), 284-304.

96. Campbell et al., Unlocking Australia's Language Potential, 66.

97. Ibid.

98. Ibid., 66-7.

99. Ibid., 60 . 
100.Ibid.

101.Ibid.

102.Ibid.

103.Ibid., 61.

104.Ibid.

105.Ken Cruickshank, 'Constructions of Language and Learner Identity in the Classroom: Confessions of a Failure,' Australian Review of Applied Linguistics 35, no. 2 (2012): 177.

106.Ibid.

107.Campbell et al., Unlocking Australia's Language Potential, 67. 108.Ibid.

109.Ibid.

110.Zeinab Ibrahim and Jehan Allam, 'Arabic Learners and Heritage Students Redefined: Present and Future,' in Handbook for Arabic Language Teaching Professionals in the 21 $1^{\text {st }}$ Century, ed. Kassem M. Wahba, Zeinab A. Taha, and Liz England (New York: Routledge, 2006), 443.

111. Campbell et al., Unlocking Australia's Language Potential, v.

112.Leal, Widening Our Horizons, xiii.

113.Campbell et al., Unlocking Australia's Language Potential, 47.

114.Peter D. P. Jones, Islamic Schools in Australia: Muslims in Australia or Australian Muslims? (Armidale: University of New England, 2013).

115. Selim, 'Arabic Teaching at Australian Islamic Schools', 292.

116. Jones, 'Islamic Schools in Australia', 281.

117. Michael Hall, 'Arabic in Australian Islamic Schools,' Babel 31, no. 2 (1996): 28-31. 